\title{
Article
}

\section{Students Who Demonstrate Strong Talent and Interest in STEM Are Initially Attracted to STEM through Extracurricular Experiences}

\author{
Amy VanMeter-Adams, ${ }^{*}$ Cara L. Frankenfeld, ${ }^{\dagger}$ Jessica Bases, ${ }^{*}$ Virginia Espina, ${ }^{*}$ \\ and Lance A. Liotta*
}

${ }^{*}$ Center for Applied Proteomics and Molecular Medicine, George Mason University, Manassas, VA 20110; ${ }^{+}$College of Health and Human Services, George Mason University, Fairfax, VA 22030

Submitted November 6, 2013; Revised July 14, 2014; Accepted August 29, 2014

Monitoring Editor: Nancy Pelaez

\begin{abstract}
What early experiences attract students to pursue an education and career in science, technology, engineering, and mathematics (STEM)? Does hands-on research influence them to persevere and complete a major course of academic study in STEM? We evaluated survey responses from 149 high school and undergraduate students who gained hands-on research experience in the 2007-2013 Aspiring Scientists Summer Internship Programs (ASSIP) at George Mason University. Participants demonstrated their strong interest in STEM by volunteering to participate in ASSIP and completing $300 \mathrm{~h}$ of summer research. The survey queried extracurricular experiences, classroom factors, and hands-on projects that first cultivated students' interest in the STEM fields, and separately evaluated experiences that sustained their interest in pursuing a STEM degree. The majority of students $(65.5 \%, p<0.0001)$ reported extracurricular encounters, such as the influence of a relative or family member and childhood experiences, as the most significant factors that initially ignited their interest in STEM, while hands-on lab work was stated as sustaining their interest in STEM (92.6\%). Based on these findings collected from a cohort of students who demonstrated a strong talent and interest in STEM, community-based programs that create awareness about STEM for both children and their family members may be key components for igniting long-term academic interest in STEM.
\end{abstract}

\section{INTRODUCTION}

"In turning toward science, it became apparent to me that science was the magic of our world and that the only reason we didn't view it as such was because of our familiarity with it" (quote from a Summer 2013 research intern). How do we ignite and retain the "magic" of science, technology, engineering, and mathematics (STEM) for our students?

DOI: $10.1187 /$ cbe.13-11-0213

Address correspondence to: Amy VanMeter-Adams (avanmete@ gmu.edu).

(C) 2014 A. VanMeter-Adams et al. CBE-Life Sciences Education (c) 2014 The American Society for Cell Biology. This article is distributed by The American Society for Cell Biology under license from the author(s). It is available to the public under an Attribution-Noncommercial-Share Alike 3.0 Unported Creative Commons License (http:/ / creativecommons.org/licenses/by-nc-sa/3.0).

"ASCB ${ }^{\circledR}$ " and "The American Society for Cell Biology ${ }^{\circledR}$ " are registered trademarks of The American Society for Cell Biology.
Answers to this fundamental educational challenge may provide strategies to attract STEM majors to fulfill the growing demand for STEM jobs (Hossain and Robinson, 2012; Wang, 2013). U.S. federal agencies projected investments of $\$ 3.4$ billion in FY2010 to support STEM (National Science and Technology Council, 2011). Funding from federal agencies and corporate entities has been allocated to programs supporting expansion of STEM education in secondary schools, recruitment and retention of students earning STEM degrees, K-12 STEM teacher professional development, and STEM workforce training. A variety of high school and undergraduate research programs have been implemented to provide students with hands-on research experiences. These programs afford students the distinctive opportunity to perform inquiry-based scientific analysis, master a technical skill set, and enhance critical-thinking skills (Thiry et al., 2011). Students taking part in hands-on programs learn to think and work like scientists and develop personal and professional skills relevant to a career in science (Seymour et al., 2004). Furthermore, these experiences can "clarify, refine, and reinforce" 
students' desire to attain STEM degrees, postbaccalaureate education, and STEM careers (Lopatto, 2004, 2007; Seymour et al., 2004). To maximize investment in these crucial programs, we need to 1) identify the factors that initially attract students to the STEM fields and 2) retain student interest in STEM degree programs. In this study, we address these important questions by querying high school and undergraduate students who had a strong talent and interest in STEM and obtained hands-on research experience in the Aspiring Scientists Summer Internship Program (ASSIP) at George Mason University (Fairfax, VA).

ASSIP was established in 2007 for high school and undergraduate students interested in STEM. Competitively selected participants volunteer $\sim 300 \mathrm{~h}$ to participate in sophisticated, original STEM research encompassing one or more of the following disciplines: proteomics, genomics, neuroscience, biochemistry, infectious disease, biodefense, bioinformatics, computer science, physics, nanotechnology, applied mathematics, bioengineering, and environmental science. The participants work one-on-one with designated volunteer faculty mentors, research scientists, and graduate students who are actively engaged in research and motivated to train and inspire future STEM leaders. As part of the 7.5-wk full-time training, the students: 1) gain hands-on experience using the latest technologies in their discipline, 2) learn to search and review scientific literature, 3) analyze and interpret experimental results, 4) practice scientific writing and communication skills, and 5) receive personal and professional guidance. In addition to working on original scientific research projects, the ASSIP students participate in scheduled career-development activities and workshops that promote creativity. Career-day seminars introduce students to a variety of STEM careers in private industry, government, academia, and healthcare.

We conducted a Web-based survey in 2012 and 2013 that was distributed to 220 alumni who participated in the 2007-2013 ASSIP as high school and/or undergraduate students. The major question we sought to answer was: What early experiences initially motivate or inspire students to pursue STEM? Previously, Hossain and Robinson predicted that science summer camps, after-school programs, science fairs, social networking, and meaningful preparation of STEM teachers attracts students into STEM fields (Hossain and Robinson, 2012). Robinson and Ochs (2008) reported that students were encouraged to enroll in more science courses when labs were integrated into the curriculum. The labs stimulated interest and created relevance to the subject. It has been suggested that programs for students, teachers, and parents would encourage precollege students to take an interest in STEM fields. The recommended programs for students included career days / fairs, field trips, test-taking skills training, academic-enrichment programs, internships, and summer jobs (Matyas and Dix, 1992). A separate study conducted by Hall et al. (2011) queried 118 high school students who participated in a 1-wk information technology academy and 107 undergraduate freshman and senior engineering students to discover what influenced their career choice of preference. The high school students reported "interest in the field" and "parents" as the most important consideration for their career choice. The undergraduate students surveyed in the Hall et al. study indicated that their career goals were influenced most by "interest in the field," followed by "earning potential," "parents," and "high school teacher." Wang evaluated recent high school graduates attending 4-yr institutions. The author concluded that motivation to pursue a STEM degree was influenced by 12th-grade math performance, exposure to math and science courses, and math self-efficacy beliefs (Wang, 2013).

The factors that ignited initial interest in STEM have not been explored in a subset of students who previously declared an interest in STEM and then participated in a hands-on summer research program. Access to this information could influence policy and programs to inspire STEM interest. How important are influences such as childhood experiences, relatives, friends, classroom encounters, teachers, media, museums, and hands-on projects in retaining student interest in STEM? We collected responses to answer this question from a diverse population of students who participated in ASSIP. The students' perceptions of the impact of a hands-on research experience on their academic readiness and their continued interest in STEM was also evaluated.

\section{METHODS}

\section{Participants}

ASSIP applicants expressed an interest in STEM at the time they applied for the program. From the applicant pool, potential summer interns were selected based on completed course work, grade point average (GPA), prior work/volunteer experience, and their personal essays, in which they described their interest in scientific research. Highly qualified applicants were invited for a personal interview with faculty scientists/mentors. The students who were accepted into the program volunteered to perform full-time, hands-on research for $7.5 \mathrm{wk}$ during the summer.

The number of ASSIP applicants and participants increased from 2007 through 2013 (Supplemental Table S1). In 2013, we received 624 applications nationwide from high school and undergraduate students. The acceptance rate, ranging from $80 \%$ in 2007 to $10 \%$ in 2013 , was reflective of the increased competitiveness and growing interest in the program (Table S1). Since the program's inception, 220 students have participated in ASSIP, 35 of whom were multiyear participants. Only ASSIP alumni who completed the summer program participated in this current study.

\section{The Survey Instrument}

The retrospective survey instrument used for the current study was approved by George Mason University's Office of Research Integrity and Assurance (protocols 8267 and 8268). The study was judged exempt from Institutional Review Board review under U.S. Department of Education guidelines. The survey, titled "ASSIP Alumni Survey," comprising 35 questions, was developed and distributed to the 2007-2013 ASSIP alumni ( $n=220$ students) using the websurvey.gmu.edu tool (Supplemental Material). Anonymous results were stored on a server at George Mason University. Demographic information including gender and ethnicity were queried. The students were asked to indicate the year(s) they participated in ASSIP, their educational status, and their current or most recent GPA. Single-option variable, multi-option variable, and unstructured-response questions 
were included to investigate the factors that inspired the ASSIP alumni's initial interest in STEM. Questions formulated using an ordinal scale (strongly agree, agree, neither agree or disagree, disagree, and strongly disagree) examined the responders' perception of their ability to 1) understand material learned in the classroom and/or read in scientific literature, 2) identify research questions and design experiments, 3) creatively solve problems inside and outside the classroom, and 4) think critically and perform scientific analysis after participating in ASSIP. Understanding of scientific research, self-confidence, continued interest in STEM, awareness of career opportunities, interest in postbaccalaureate education and STEM careers, and preparedness for advanced degrees and STEM careers after ASSIP were also evaluated using the same ordinal scale. Multi-option variable questions were included to assess students' academic and career goals.

\section{Data Collection and Statistical Measurements}

The anonymous survey was conducted in two stages: first with alumni from the 2007-2011 programs and then with alumni from the 2012-2013 programs. The first set of data were collected on November 15, 2012, from 58/118 students in the 2007-2011 group. The second set of data were collected from 46/50 2012 ASSIP alumni and 54/62 2013 ASSIP alumni within the same year they completed their respective programs. The denominator in the 2012 and 2013 groups reflects multiyear participants. Ten of 112 responders in the 20122013 group participated in ASSIP for more than 1 yr. Surveys submitted by nine returning students from the 2012 and 2013 ASSIP classes were not considered for analysis in this study in order to prevent duplicate responses. One returning student in the 2013 class did not complete the survey. The usable survey response rate (total usable/participants) was $49.2 \%$ (58/118), $84.0 \%$ (42/50), and $79.0 \%$ (49/62) for the 2007-2011, 2012, and 2013 ASSIP alumni surveys, respectively. The usable overall response rate was $67.8 \%(149 / 220)$.

Data collected from the 2007-2011 and 2012-2013 groups were independently evaluated to compare responses from 1) a population of students who submitted the survey at least $1 \mathrm{yr}$ after completing the program and 2) a separate population of students who submitted the survey immediately after the program concluded. Means and percentages were calculated as summary statistics to make comparisons across groups. The two-tailed Fisher's exact test, two-tailed chi-square with Yates' correction, and two-tailed chi-square without Yates' correction were used to calculate $p$ values. Probability values from the two-tailed Fisher's exact test are reported, and statistical significance was only considered when $p$ values $<0.05$ were recorded for all three tests. For some variables, participants could select more than one possible response; therefore, the denominator may be greater than the number of alumni.

\section{RESULTS}

\section{Study Population and Response Rate}

The distribution of men (46.3\%) and women (45.6\%) who responded to the 2007-2013 ASSIP alumni surveys was nearly identical. Twelve students did not disclose their gender. The ethnic distribution was $47.0 \%$ Asian, 0.7\% American Indian or Alaskan Native, $2.7 \%$ black or African American,
$4.7 \%$ Hispanic/Latino origin, $0.7 \%$ Native Hawaiian or other Pacific Islander, $32.2 \%$ white, and $4.0 \%$ being of two or more races. Eight percent did not disclose their ethnicity. Based on data collected from the 2012-2013 classes on the first day of the program, the large proportion of Asian survey responders was representative of the total population of Asian students who participated in the program. In the 2012 and 2013 classes, 44 and $51 \%$ of students were Asian, respectively. Regarding gender, the 2012 class was $60 \%$ male $/ 40 \%$ female, while the 2013 class was $47 \%$ male $/ 49 \%$ female. The ethnicity and gender of the 2007-2011 cohorts was not recorded before or during program enrollment. The participants evaluated in this survey earned GPAs of 4.0 (34.2\%), 3.5-3.99 (46.3\%), and 3.0-3.49 (18.1\%). Two students did not report their GPAs.

Responses were evaluated from 131 students who participated in ASSIP for $1 \mathrm{yr}, 17$ students who participated for $2 \mathrm{yr}$, and 1 student who participated for $3 \mathrm{yr}$. The population is composed of alumni who participated as high school students $(59.1 \%)$, undergraduate students $(32.2 \%)$, or as both high school and undergraduate students (7.4\%). Two participants did not indicate their educational status as an ASSIP participant. The multiyear participants volunteered in our internship program as high school students, undergraduate students, or both high school and undergraduate students (Table S2). Each student only submitted one survey.

Total enrollment in the first $3 \mathrm{yr}$ of our summer program was purposefully restricted due to limited university resources and community awareness for this inaugural program. Thus, fewer alumni were available to respond to the survey. This study evaluated alumni from the $2007(n=5)$, $2008(n=5), 2009(n=17), 2010(n=20), 2011(n=30), 2012$ $(n=42)$, and $2013(n=49)$ programs, which included multiyear participants from the 2007-2011 group. Survey response rates for each respective year are included in Figure 1.

\section{Factors That Influenced Initial Interest in STEM}

We compared the 2007-2011 and 2012-2013 cohorts to determine whether the survey data were biased by the length of time that existed between ASSIP program completion and

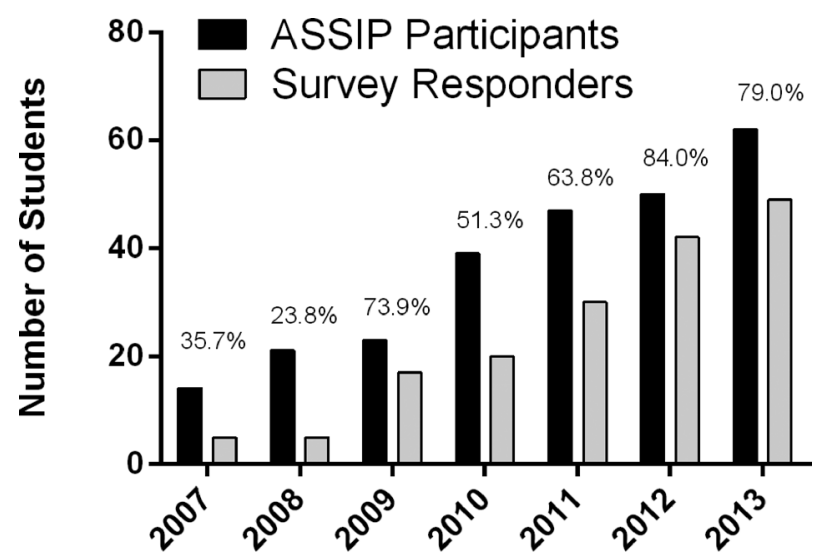

Figure 1. ASSIP survey response rate. The ASSIP alumni survey was distributed to all students who participated in the 2007-2013 programs. The data illustrate the number of participants who received the questionnaire and the number of survey responders from each respective class who were included in the analysis for this study. The response rate is denoted for each year. 
survey submission. The 2007-2011 cohort was grouped to create a sufficient population size and was surveyed at different time points (1-5 yr) after their ASSIP experiences. The 2012-2013 cohort submitted the survey immediately after completing the program.

The factors that ignited students' interest in STEM were divided into three groups: extracurricular experiences, classroom experiences, and hands-on projects. Extracurricular experiences were classified as: 1) relative or friend who introduced the student to STEM; 2) childhood experience or encounter with nature, astronomy, and so on; 3) fiction or nonfiction book, television show, or movie; and 4) visiting a museum. Classroom influences comprised 1) performing laboratory experiments in class and 2) a high school teacher. A hands-on project was defined in the survey as "a hands-on project such as a science fair or research experience" and was analyzed as an independent group (Figure 2), because it can be performed inside or outside the classroom. Among many possibilities, a hands-on project could have referred to a project completed for a science fair competition, a project assigned during a summer camp, or a formal research experience like ASSIP.

We first evaluated the single most influential experience type that initially ignited students' interest in STEM. This survey question was a single-variable response. Substantially more students from both the 2007-2011 (Figure 2B) and the 2012-2013 (Figure 2C) programs reported that extracurricular experiences (60.7 and 68.5\%, respectively) led to their initial interest in STEM compared with classroom experiences (19.6 and 18.0\%, respectively; $p<0.0001$ ) and hands-on projects (19.6 and $13.5 \%$, respectively; $p<0.0001$ ). Next, we evaluated each factor independently. As described in Figure 2A, both the 2007-2011 and 2012-2013 groups reported that childhood experiences such as an encounter with nature, astronomy, and so on (24.1 and $25.3 \%$, respectively) or a relative or friend who introduced them to science, technology, engineering, or math (27.6 and $28.6 \%$, respectively) were the strongest factors that ignited their initial interest in STEM. There was no significant difference between the two cohorts $(p=1.0)$. No statistically significant difference was found between the 2007-2011 and 2012-2013 groups regarding the number of students who were most strongly influenced by a high school teacher (6.9 and $14.3 \%$, respectively; $p=0.1958)$, nonfiction media (5.2 and $4.4 \%$, respectively; $p=$ $1.0)$, fiction media (1.7 and $8.8 \%$, respectively; $p=0.1545)$, visiting a museum (0 students), or participating in a hands-on project such as a science fair or research experience (19.0 and $13.2 \%$, respectively; $p=0.3605$; Figure $2 \mathrm{~A}$ ). The percentage of students who acknowledged performing experiments in class was the strongest factor that ignited their initial interest in STEM was different between the 2007-2011 (12.1\%) and $2012-2013(3.3 \%)$ cohorts $(p=0.0475$, Fisher's exact test only; Figure 2A).

The influential experience types noted above were derived from a survey question which asked students to indicate the strongest factor that influenced their initial interest in STEM. A separate, multivariable-response question in the survey allowed students to acknowledge the collective experiences that ignited or contributed to their initial interest in the field. Similar to the responses received for the strongest factor that led to an interest in STEM, significantly more responses were recorded from students in both the 2007-2011 and 2012-2013 groups (Figure 2, E and F) for extracurricular experiences (55.9 and $58.4 \%$, respectively) compared with classroom experiences (25.9 and $25.5 \%$, respectively; $p<0.0001$ ), and a hands-on project such as science fair or research experience (18.2 and $16.1 \%$, respectively; $p<0.0001$ ). When we assessed all factors independently, we found that many types of factors contributed to 2007-2011 and 2012-2013 students' initial interest in STEM: childhood experiences such as an encounter with nature, astronomy, and so on (20.2 and $16.8 \%$, respectively; $p=0.3844$ ), a relative or friend who introduced them to science, technology, engineering, or math (17.4 and $18.6 \%$, respectively; $p=0.8042$ ), participation in a hands-on project such as a science fair or research experience (17.4 and $15.7 \%$, respectively; $p=0.6978$ ), high school teacher (12.4 and $14.3 \%$, respectively; $p=0.5788)$, and classroom experiments (12.4 and $10.7 \%$, respectively; $p=0.6509$; Figure 2D).

As reported above, data collected from the 2007-2011 and 2012-2013 alumni did not differ significantly on questions that addressed the strongest factor and all factors that contributed to the students' initial interest in STEM. A significant majority of the students also perceived that the hands-on research experience they gained in ASSIP played a role in their continued interest in STEM. The results did not differ between the 2007-2011 and 2012-2013 cohorts ( $p>0.3638$; Figure 3 ). On the basis of the observation that the findings were replicated among separate groups of students, we combined all responses from the 2007-2013 classes (Figure 4).

Gender and cultural and ethnic background could influence the factors that ignited the students' initial interest in STEM. To compare the ethnicity of the 2007-2013 survey responders for each of the factors that inspired their initial interest in STEM, we categorized the students' ethnicity into four groups: 1$)$ Asian $(n=70), 2)$ white $(n=48), 3)$ other $(n=19)$ and 4$)$ not disclosed $(n=12)$. A population of 19 students who were American Indian or Alaskan Native, black or African American, Hispanic/Latino, and Native Hawaiian or other Pacific Islander was classified as "other" to create a group large enough to compare in this study. Based on these categories, there was no significant difference by ethnicity $(p>0.5707)$ for any of the factors that inspired initial interest in STEM (Supplemental Figure S1). Moreover, there was no difference in the gender of the students for the factors that ignited their initial interest in STEM $(p>0.2575)$. These findings must be considered with the limitation that the ethnicity and gender of all 2007-2011 participants cannot be compared with the gender and ethnicity of the 2007-2011 survey responders.

In a multivariable-response question, some of the survey responders reported additional personal details about the factors that ignited their initial interest in STEM. Thirteen students who listed other influences noted "a relative dying of cancer," "curiosity," "Bill Nye the Science Guy," "a personal experience," "the Discovery Channel," "ancient philosophy," "high school biology and psychology classes," "a microbiology professor," "interest in becoming a positive contributing member of society," "competitions," "the condition of society and world," "the people around me," and "I was good at it." Anecdotally, we learned more about the survey responders' initial interest in STEM from an unstructured-response question. Collectively, of the 50 students who responded to the question, many indicated a culmination of experiences that were influential in their initial attraction to the STEM fields. 


\section{Strongest factor that ignited initial interest in STEM}

A.

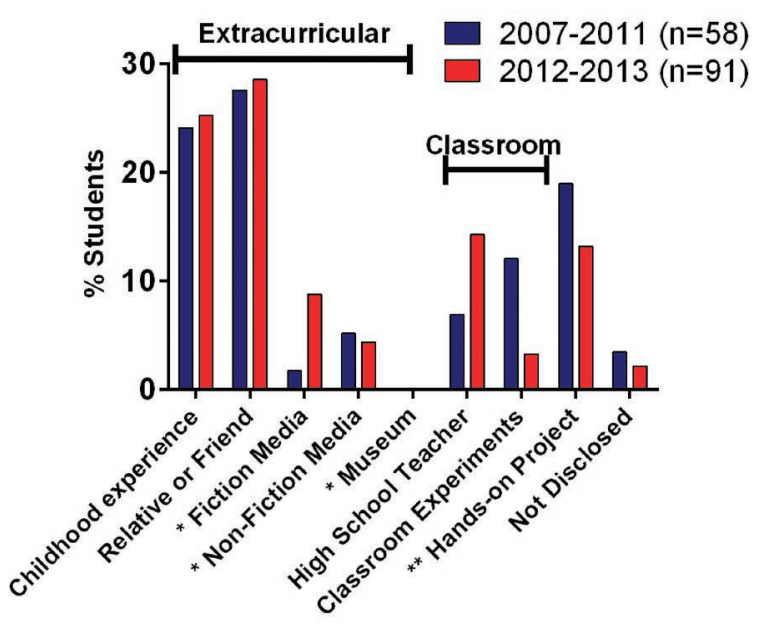

B.

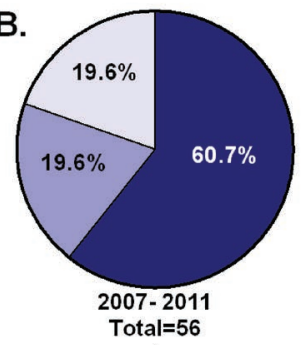

c.

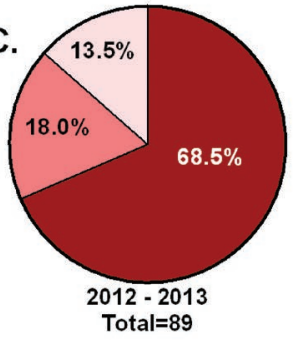

Extracurricular

Classroom

Hands-on project**

Extracurricular

Classroom

Hands-on project*

\section{All factors that ignited initial interest in STEM}

D.

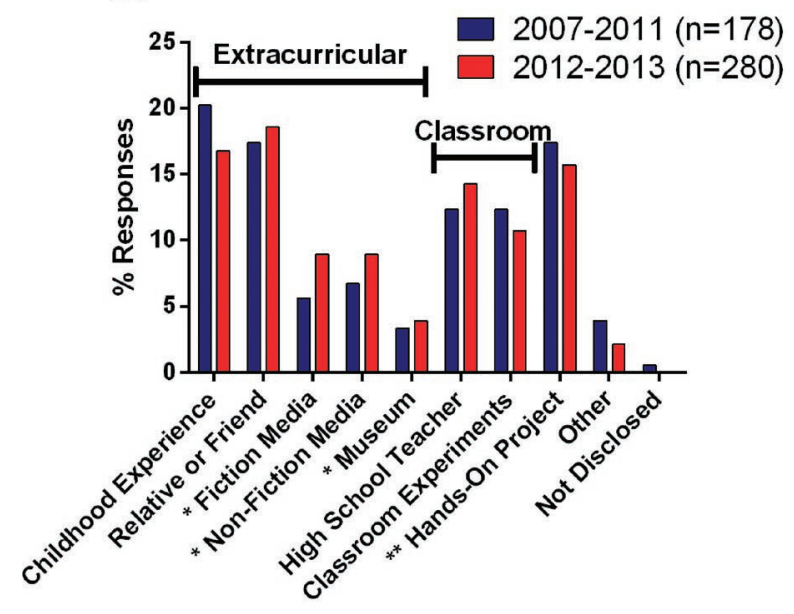

E.

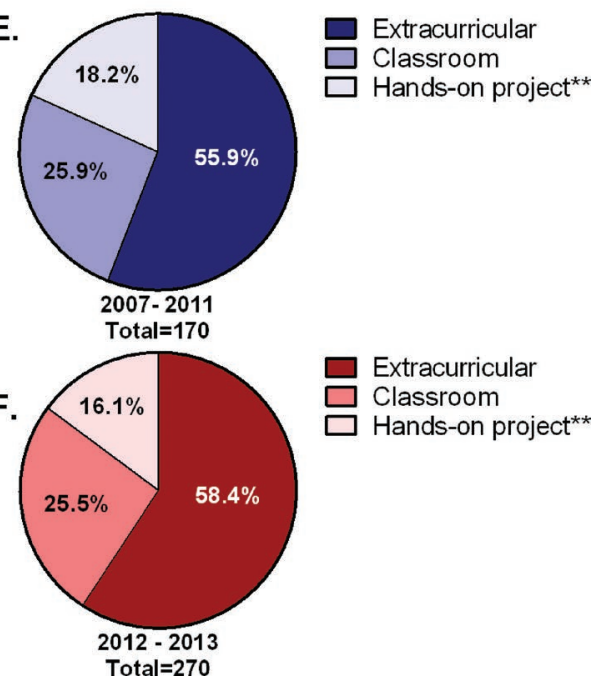

Figure 2. Comparison of 2007-2011 and 2012-2013 study sets: extracurricular experiences ignited ASSIP alumni's initial interest in STEM. Significantly more participants from the 2007-2011 and 2012-2013 classes were initially influenced to pursue STEM by nonclassroom experiences compared with in-classroom experiences and hands-on projects $(p<0.0001)$. The students reported both the strongest factor and all factors that ignited their initial interest in STEM. Each factor was analyzed individually, and the factors were grouped into three categories: classroom experiences, extracurricular experiences, and hands-on projects. Extracurricular influences included 1) relative or friend who introduced the student to STEM; 2) childhood experience or encounter with nature, astronomy, and so on; 3) fiction or nonfiction book, television show, or movie; and 4) visiting a museum. In-classroom influences included 1) performing laboratory experiments in class and 2) a high school teacher. A hands-on project such as a science fair or research experience was classified as its own category **, because it could be performed inside or outside the classroom. ${ }^{*}$, experiences that can be extracurricular or assigned in the classroom. Responses from the 2007-2011 and 2012-2013 study sets were compared. (A) The 2007-2011 and 2012-2013 responses were plotted to compare the strongest factor that ignited initial interest in STEM. (B) Responses from the 2007-2011 ASSIP alumni who reported the strongest factor that ignited their interest in STEM are represented as extracurricular, classroom, and hands-on projects. Students who did not disclose the strongest factor that ignited their interest in STEM are not represented in the circle graph $(n=2)$. (C) 2012-2013 ASSIP alumni responses to the strongest factor that ignited their interest in STEM are reported as extracurricular, classroom, and hands-on projects. Students who did not disclose the strongest factor that ignited their interest in STEM are not represented in the circle graph $(n=2)$. (D-F) All factors that influenced the alumni's initial interest in STEM are reported and compared across the 2007-2011 and 2012-2013 study sets. The circle graph does not depict students who did not respond to the question (2007-2011: $n=1 ; 2012-2013: n=0)$ or selected other $(2007-2011: n=7 ; 2012-2013: n=6)$. 


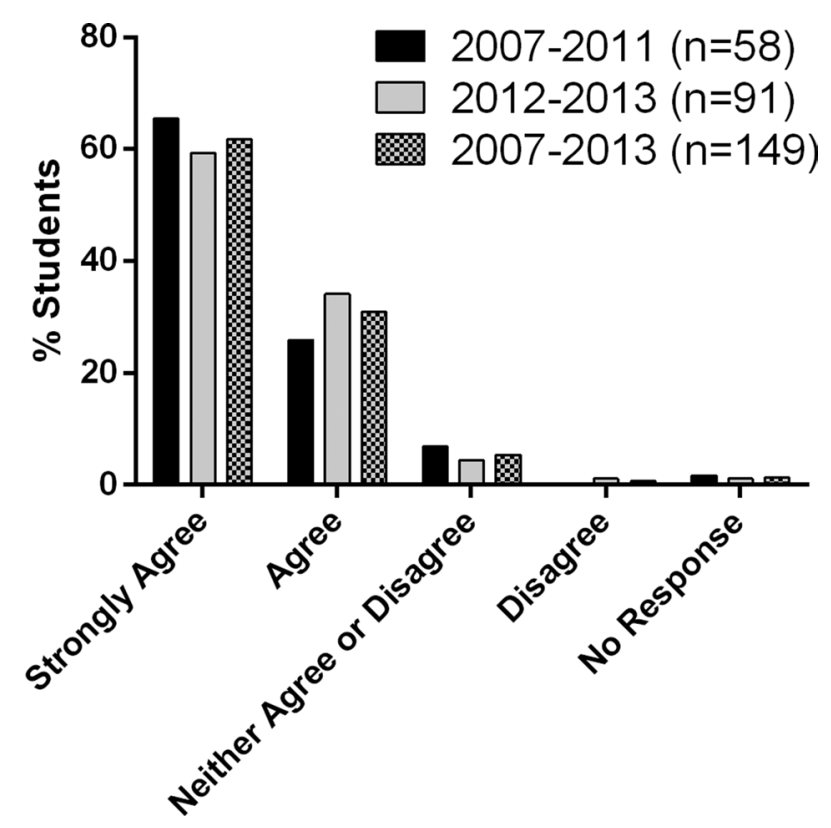

Figure 3. ASSIP contributed to a continued interest in STEM. Data are reported from the ASSIP alumni regarding their perception that the hands-on research they gained in ASSIP influenced their continued interest in STEM. Data are reported from the 2007-2011 $(n=58)$ and 2012-2013 $(n=91)$ cohorts. Total responses from the 2007-2013 alumni $(n=149)$ are also illustrated. The data are presented as a percentage of students from each cohort.

Ten of 50 alumni who indicated that they were most inspired by classroom experiences provided written descriptions depicting the sources of their inspiration. Elementary and middle school classroom experiences or the influence of elementary and middle school teachers were not specifically delineated as answer prompts for the questions that assessed the factors that inspired the alumni's initial interest in STEM. Nevertheless, 8/50 survey responders who answered the free-response question did acknowledge elementary and middle school experiences. The students' written responses acknowledged middle school and high school teachers who taught physics, biology, chemistry, and neurobiology. Specifically, the alumni noted charismatic, enthusiastic teachers who took great interest in their students and made the subjects very interesting. They also mentioned non-textbookbased activities, such as "dissecting a frog," "attending a university enrichment camp," and "developing a science project." One alumna commented, "I really became interested in science (specifically neurology) when my teacher in middle school read us a book about Phineas Gage and explained to us how the brain worked."

Eight of 50 alumni who indicated that they were most inspired by hands-on projects such as science fairs or research experiences provided additional text elaborating on these experiences. The students acknowledged their experiences in ASSIP, STEM research programs, projects assigned in the classroom, independent research, and science fair competitions. Specifically, one student responded, "I had designed and coded a difficult Guitar Hero program in Java in intro to computer science, and though it required many hours outside of school and had many problems, my partner and I were able to get it to work. We did more than was expected of us for that project and it was nice to use what I knew and apply it to any situation."

Thirty of 50 alumni who recognized extracurricular experiences such as a relative or friend, childhood experience, nonfiction media, or fiction media as the strongest factor that inspired their initial interest in STEM provided additional details about their encounters. The alumni acknowledged parents and other relatives who were employed in STEM or medical fields, brothers and sisters who shared scientific literature and encouraged them to take advanced science courses, and a personal or family member's illness. The students also recognized visiting nature parks, identifying insects, playing with Legos, using microscopes, going to museums, reading science-oriented books, and watching nature television programs. One alumna commented, "My mom is a neurologist so since childhood I have been exposed to different neurological cases, diseases, and symptoms." Another student commented, "I attended a loggerhead sea turtle research trip with my brother when I was younger. This really sparked my interest in nature. Afterwards, I always wanted to know more about animals and science." A home-schooled alumnus exclaimed, "I was strongly encouraged to explore my interests outside of the material we covered in school, so I was always reading more about my interests, playing Legos (and building enormous structures of everything ranging from a Star Trek inspired star ship, to a scaled model of a space shuttle and space station), playing with microscopes, going to museum trips, etc." Another alumnus commented, "I was questioning why, in so many books that I read, magic existed, yet in our world, it did not. In turning toward science, it became apparent to me that science was the magic of our world and that the only reason that we did not view it as such was because of our familiarity with it."

Two of 50 alumni who did not identify the strongest factor that inspired their initial interest in STEM in the single-option variable question provided information about the source for their inspiration in the unstructured-response question. One student noted, "Availability of STEM jobs and growing need for scientists and engineers in America." Another acknowledged, "Looking at the state of the society and the world, it is imperative that we contribute for the betterment of the people collectively and not just an individual or a business."

\section{Influence of Hands-On Research on Scientific and Academic Performance}

We were interested in learning how a hands-on research experience potentially impacts this cohort of students' perceptions of their academic readiness as well as their continued interest in STEM. Nearly 97\% of the 2007-2013 alumni reported that they gained a better understanding of scientific research (73.2\% strongly agreed and 23.5\% agreed); $83.9 \%$ noted that they better understood material learned in the classroom and/or read in scientific literature (47.0\% strongly agreed and $36.9 \%$ agreed); $87.9 \%$ responded that they were more proficient at identifying research questions and designing experiments (47.0\% strongly agreed and $40.9 \%$ agreed); $79.2 \%$ documented that they more creatively solve problems inside and outside of the classroom (37.6\% strongly agreed and $41.6 \%$ agreed); $89.9 \%$ said that they had enhanced critical-thinking and scientific analysis skills (52.3\% strongly agreed and $37.6 \%$ agreed); and $77.2 \%$ noted that 


\section{7-2013 ASSIP Alumni: Strongest factor that ignited interest in STEM}
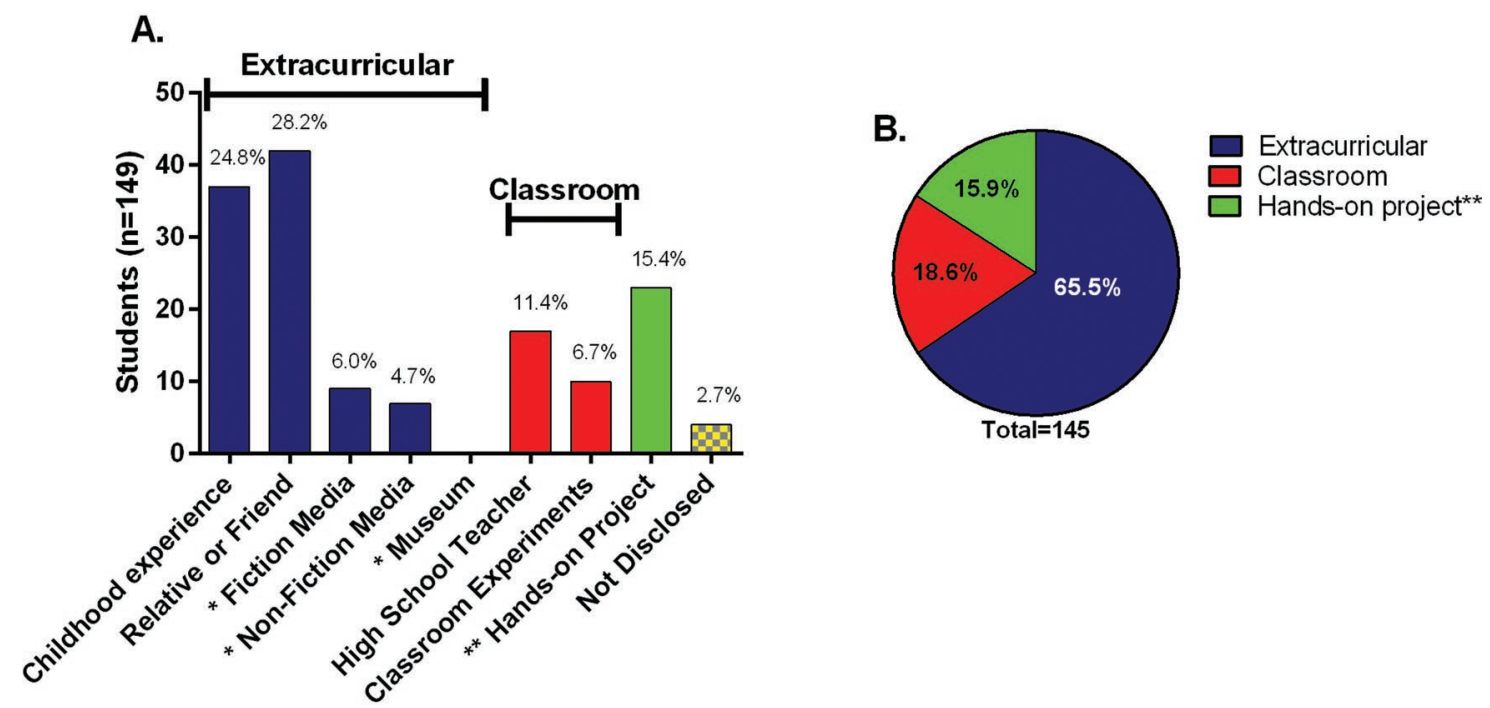

\section{7-2013 ASSIP Alumni: All factors that ignited interest in STEM}

C.

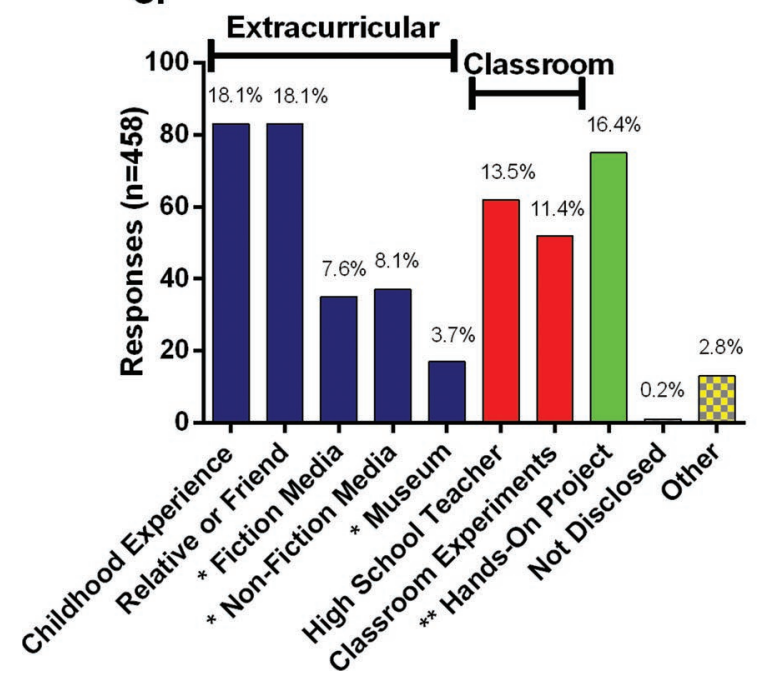

D.

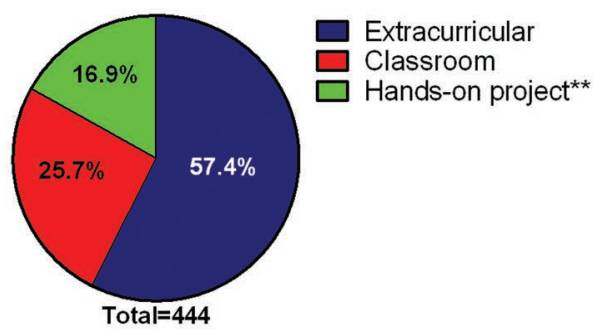

Figure 4. The total population of 2007-2013 ASSIP alumni reporting that extracurricular experiences ignited their initial interest in STEM. Significantly more 2007-2013 ASSIP alumni were initially influenced to pursue STEM by extracurricular experiences compared with classroom experiences and hands-on projects $(p<0.0001)$. The students reported both the strongest factor and all factors that ignited their initial interest in STEM. Each factor was analyzed individually, and the factors were grouped into three categories: extracurricular experiences, classroom experiences, and hands-on projects. Extracurricular influences included 1) relative or friend who introduced the student to STEM; 2) childhood experience or encounter with nature, astronomy, and so on; 3) fiction or nonfiction book, television show, or movie; and 4) visiting a museum. In-classroom influences included 1) performing laboratory experiments in class and 2) a high school teacher. *, experiences that can be extracurricular or assigned in the classroom. ${ }^{* *}$, a hands-on project such as a science fair or research experience was classified as its own category because it can be performed inside a classroom or in an extracurricular environment. (A) Each factor was plotted independently to illustrate the strongest factors that influenced the 2007-2013 ASSIP alumni's initial interest in STEM. (B) The strongest factors that influenced the 2007-2013 alumni's initial interest in STEM are reported as three distinct categories: extracurricular experiences, classroom experiences, and hands-on projects. Students who did not disclose the strongest factor that ignited their interest in STEM are not represented in the circle graph $(n=4)$. (C and D) All factors that influenced the 2007-2013 ASSIP alumni's initial interest in STEM are reported as the total number of responses for each factor. The circle graph does not depict students who did not respond to the question $(n=1)$ or selected other $(n=13)$.

they had more self confidence $(40.3 \%$ strongly agreed and $36.9 \%$ agreed; Figure 5A). When we analyzed the 2007-2011 and 2012-2013 cohorts' perceptions of their academic and scientific progress, we did not find significant differences between the two groups ( $p>0.3147$; Figure S2). The data were collected from a retrospective survey and did not compare 
A.

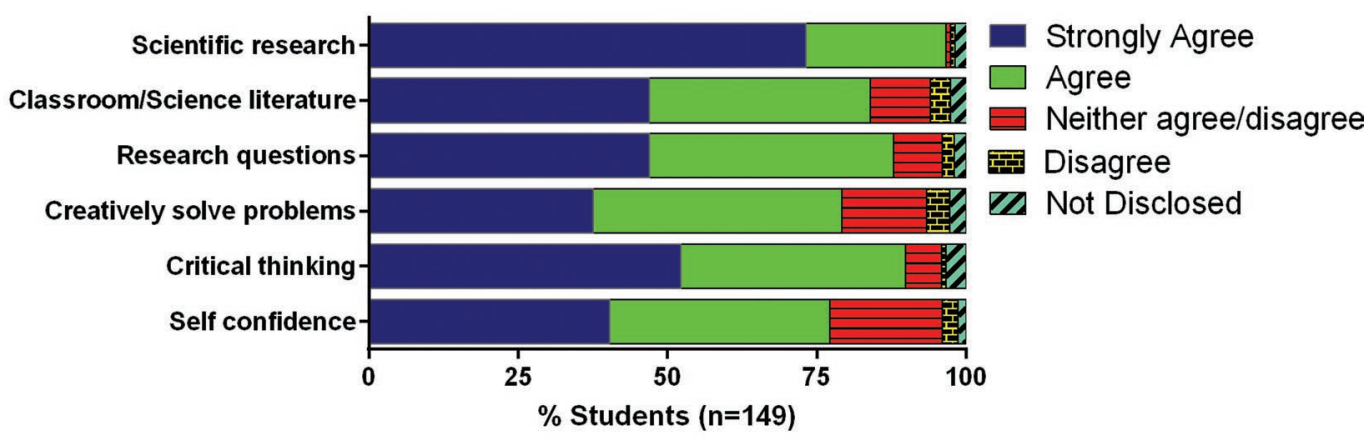

B.

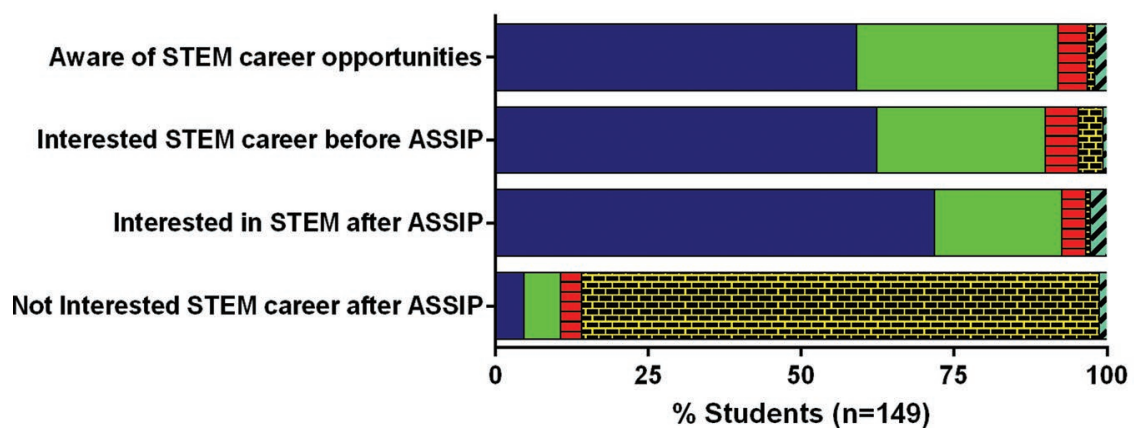

Figure 5. (A) ASSIP positively influenced the participants' scientific and academic performance. The 2007-2013 ASSIP alumni indicated their perception of the impact ASSIP had on 1) gaining a greater understanding of scientific research, 2) better understanding material learned in the classroom and/or read in scientific literature, 3) more efficiently identifying research questions and designing experiments, 4) creatively solving problems inside and outside the classroom, 5) enhanced critical-thinking and scientific analysis skills, and 6) greater self-confidence. The data are reported as a percentage of the total number of students $(n=149)$. (B) ASSIP alumni are interested in pursuing STEM careers. The 2007-2013 alumni reported an increased awareness of STEM career opportunities after participating in ASSIP and interest in pursuing a STEM career before and after participating in the program. The values are recorded as a percentage of the total number of students $(n=149)$.

each student's self-perception before participating in ASSIP with his or her self-perception after participation.

\section{Degree Topics Selected by STEM Students}

We inquired about the most advanced degree the 2007-2013 ASSIP alumni planned to pursue and the disciplines they intended to study. To address the first question, we asked the students to recall the most advanced degree they desired to pursue before participating in ASSIP and to indicate their current degree aspirations (Table 1). Thirty-one percent of the responders reported a change in their degree aspirations after participating in ASSIP. While $69.6 \%$ of students who

Table 1. ASSIP alumni indicated their degree preference before and after participating in ASSIP

\begin{tabular}{|c|c|c|}
\hline Degree preference & Before ASSIP $(n=149)$ & After ASSIP $(n=149)$ \\
\hline Associate's degree & $2(1.3 \%)$ & 0 \\
\hline Bachelor's degree & $19(12.8 \%)$ & $9(6.0 \%)$ \\
\hline Master's degree & 27 (18.1\%) & $33(22.1 \%)$ \\
\hline $\mathrm{PhD}$ & $39(26.2 \%)$ & $40(26.8 \%)$ \\
\hline MD & $48(32.2 \%)$ & $45(30.2 \%)$ \\
\hline $\mathrm{MD} / \mathrm{PhD}$ & $9(6.0 \%)$ & $18(12.1 \%)$ \\
\hline DDS & 0 & $2(1.3 \%)$ \\
\hline Not disclosed & $5(3.4 \%)$ & $2(1.3 \%)$ \\
\hline
\end{tabular}

changed their degree preference chose a more advanced degree, $15.2 \%$ chose a less advanced degree. Our scale for determining the lowest to highest level degree is associate's, bachelor's, master's, PhD, MD, and dual MD/PhD. Nearly $11 \%$ did not disclose a degree preference before ASSIP but acknowledged a degree of interest upon survey completion. Four percent indicated a degree interest before ASSIP but did not disclose a degree preference at the time of survey completion. The percentage of students from each class who changed their degree preference ranged from 20 to $40 \%$ (Table S3). It is of interest to note that nearly $74 \%$ of students who previously planned to stop their educational pursuits after earning a bachelor's degree were interested in obtaining an advanced degree. This cohort of 19 students indicated a desire to earn a master's degree $(47.4 \%)$, MD $(15.8 \%)$, or $\mathrm{PhD}(10.5 \%)$. Slightly more than $26 \%$ of this cohort did not change their degree preference.

The 2007-2013 ASSIP alumni expressed intentions of earning undergraduate degrees in a variety of STEM fields. The most popular academic programs included biology $(26.4 \%)$, engineering $(14.8 \%)$, neuroscience $(12.1 \%)$, and chemistry (11.2\%; Table 2). Medicine (22.0\%), biology (15.4\%), engineering $(9.8 \%)$, neuroscience $(9.3 \%)$, and chemistry $(8.9 \%)$ were the most popular intended graduate/professional degree programs (Table 2). Two of the responders who reported disinterest in pursuing a graduate degree and 13 students who indicated interest in earning a graduate degree, did not 
Table 2. ASSIP alumni reported their undergraduate and graduate degree field of study intentions

\begin{tabular}{lcc}
\hline \multicolumn{1}{c}{ Field of study } & $\begin{array}{c}\text { Undergraduate } \\
\text { degree intentions } \\
(n=223 \text { responses) }\end{array}$ & $\begin{array}{c}\text { Graduate degree } \\
\text { intentions }(n=214 \\
\text { responses) }\end{array}$ \\
\hline Biology & $59(26.4 \%)$ & $33(15.4 \%)$ \\
Business & $9(4.0 \%)$ & $7(3.3 \%)$ \\
Chemistry & $25(11.2 \%)$ & $19(8.9 \%)$ \\
Education & $2(0.9 \%)$ & $2(0.9 \%)$ \\
Engineering & $33(14.8 \%)$ & $21(9.8 \%)$ \\
Mathematics & $14(16.3 \%)$ & $7(3.3 \%)$ \\
Medical technology & $6(2.7 \%)$ & $6(2.8 \%)$ \\
Neuroscience & $27(12.1 \%)$ & $20(9.3 \%)$ \\
Nursing & $2(0.9 \%)$ & $1(0.5 \%)$ \\
Physics & $14(6.3 \%)$ & $9(4.2 \%)$ \\
Public health & $8(3.6 \%)$ & $8(3.7 \%)$ \\
Dentistry & $\mathrm{NA}$ & $3(1.4 \%)$ \\
Law & $\mathrm{NA}$ & $1(0.5 \%)$ \\
Medicine & $\mathrm{NA}$ & $47(22.0 \%)$ \\
Other & $22(9.9 \%)^{\mathrm{a}}$ & $12(5.6 \%)^{\mathrm{b}}$ \\
Not disclosed & $2(0.9 \%)$ & $18(8.4 \%)$ \\
\end{tabular}

The number of responses from the 2007-2013 alumni for desired field of study in an undergraduate and graduate degree program was recorded. Survey responders could identify multiple fields of study.

a Other undergraduate degree fields of study that were not listed as answer prompts included astronomy, biochemistry, biomedical engineering, biotechnology, classics, computational data sciences, computer science, economics/premed, environmental science, evolutionary anthropology, political science, and psychology.

bother graduate degree fields of study that were not listed as answer prompts included astronomy, biodefense, biotechnology, computer science, environmental science, physiology, and oncological neurosurgery.

select a specific field of study. Nine of 12 students who were unsure of their graduate degree intentions did list a potential field of STEM study.

\section{Student Career Aspirations}

During our 7.5-wk summer program, students attended workshops designed to introduce a variety of STEM career opportunities. After participating in career-day workshops, $92.0 \%$ of the survey responders perceived that they were more aware of scientific career opportunities (59.1\% strongly agreed and $32.9 \%$ agreed; Figure $5 \mathrm{~B}$ ). We also compared students' confidence in pursuing future STEM employment before and after ASSIP. Nearly 90\% of the 2007-2013 alumni recalled that they would pursue STEM employment before participating in ASSIP $(62.4 \%$ strongly agreed and $27.5 \%$ agreed) and $92.6 \%$ of the survey responders agreed that they would pursue STEM employment after participating in the program $(71.8 \%$ strongly agreed and $20.8 \%$ agreed; Figure 5B). Fourteen students who were not committed to pursuing STEM employment before participating in ASSIP $42.9 \%$ disagreed and $57.1 \%$ neither agreed nor disagreed) were further evaluated. Nearly $29 \%$ of the students strongly agreed and $28.6 \%$ agreed that they would pursue a STEM career after participating in the program. We subdivided the entire group of responders into 2007-2011 and 2012-2013 cohorts. There was no significant difference between the groups regarding their awareness of STEM career opportunities, interest in a STEM career before and after ASSIP, and disinterest in a STEM career ( $p>0.0840$; Figure S3).

Most students planned to seek careers in healthcare $(32.2 \%)$ and laboratory/scientific research (30.97\%). Other employment interests included engineering (13.1\%), science-related administrative careers $(7.6 \%)$, education $(6.8 \%)$, computer science $(5.1 \%)$, non-STEM related employment $(3.0 \%)$, and other careers $(1.3 \%)$. Written responses included careers in "bioengineering," "military," and "zoo veterinary medicine." One alumnus did not report a career field of interest.

\section{DISCUSSION}

While the factors that motivate students to pursue STEM are acknowledged in the literature (Matyas and Dix, 1992; Robinson and Ochs, 2008; Hall et al., 2011; Hossain and Robinson, 2012; Wang, 2013), the importance of factors inside and outside the classroom have not been explored in a population of students who 1) excel academically, 2) have demonstrated and declared interest in STEM by volunteering to participate in STEM hands-on research programs, and 3) state they intend to pursue an education track and a career in STEM. The present study does not evaluate "change strategies" (Henderson et al., 2011) for attracting students into STEM. Instead, our goal was to learn what experiences initially captured the students who demonstrate strong talent and interest in STEM. Our data reveal the unexpected importance of extracurricular experiences that initially attract students to STEM. Specifically, a majority of this study population who demonstrated strong talent and interest in STEM indicated that nonclassroom encounters, including childhood experiences with nature, astronomy, and so on, and relatives or friends who introduced them to STEM were the strongest factors that sparked their initial interest in the field.

Although it is important to identify the strongest factors that ignite most students' initial interest in STEM, it is imperative not to discount the influence other experiences have on different cohorts of students (Kabacoff et al., 2013). In-classroom factors, including high school teachers and classroom experiments and hands-on projects such as science fair or research experiences, were also noted by a smaller population of alumni as the strongest factors that inspired their initial interest in STEM. A limitation of this study is that we omitted references to elementary and middle school from the specific answer options inquiring about students' initial interest in STEM. This should be taken into consideration when interpreting these data. Nevertheless, the students were asked to indicate the factor that most influenced them to pursue STEM. Survey answer prompts included specific choices relating to nonclassroom experiences such as family, friends, and childhood experiences, or encounters with nature, astronomy, and so on. While childhood experiences or relatives and friends are not expected to be directly related to the elementary and middle school classroom, other specific choices such as visiting museums, reading books, or watching fictional and nonfictional STEM-centered media could have been assigned by teachers. A significant 
percentage $(53 \%)$ of responders reported they were "most influenced" by family, friends, and childhood experiences (Figure 4A). We do not want to minimize the potential role of classroom-associated reading assignments and museum field trip activities. Museums, fiction media, and nonfiction media that logically constitute extracurricular activities account for $10.7 \%$ (Figure $4 \mathrm{~A}$ ) of the total responses and could have been influenced by educational experiences or teacher recommendations.

Students who participated in our hands-on research program perceived that they gained a greater understanding of scientific research, developed enhanced critical-thinking and scientific analysis skills, better understood material learned in the classroom and read in scientific literature, were more proficient at identifying research questions and designing experiments, and more creatively solved problems inside and outside the classroom. These findings are not unexpected and are supported by previous findings. Thiry et al. (2011) acknowledged that hands-on research stimulates increased communication, technical and research skills; critical thinking; and scientific analysis. It has also been reported that undergraduate students who participated in hands-on research reported greater efficiency in reading scientific literature, identifying research questions, designing an experiment, analyzing and interpreting data, and communicating research orally and in written form (Kardash, 2000; Lopatto, 2004; Junge et al., 2010).

Prior studies indicate that students who participate in hands-on research report improvements in GPA, successful completion of science courses, and increased desire to pursue STEM degrees. These experiences promote expectations for graduate studies, encourage attainment of graduate STEM degrees, and solidify career aspirations (Knox et al., 2003; Barlow and Villarejo, 2004; Markowitz, 2004). Retention rates were improved for students in STEM degree programs when peers with similar interests were placed in an environment together, such as that provided by undergraduate research programs (Knox et al., 2003; Pender et al., 2010). Our data are consistent with these observations. The ASSIP alumni reported that they: 1) developed skills that support academic excellence and are essential for becoming innovative STEM professionals, 2) solidified their undergraduate and graduate degree interests, and 3) are more aware of STEM career opportunities and are committed to pursuing STEM careers. Interpretation of the findings should take into account that a control group does not exist and we are reporting the responders' perceptions.

The most frequently noted academic fields of study were similar to the STEM research areas the students explored in ASSIP. Initially, ASSIP paired students with mentors who were performing life sciences research. As the number of students and mentors in our program expanded, we have added STEM mentors in various university departments. The most popular undergraduate degree program was biology. A majority of students who planned to seek a postbaccalaureate degree were interested in medicine and biology. Approximately $90 \%$ of the mentors performed research in genomics, proteomics, nanotechnology, neuroscience, bioinformatics, biochemistry, and environmental science. Additional mentors from the math and engineering departments were recruited in 2012, which we believe will cause a shift in the students' future educational and career field aspirations.
A limitation of this study is the cross-sectional, retrospective survey tool used to evaluate the students' perceptions. While offering pre-post surveys to the same population may prevent sources of bias associated with recall, social desirability, effort justification, and cognitive dissonance (Hill and Betz, 2005), we chose to use a cross-sectional, retrospective survey to avoid response-shift bias (Howard, 1980; Moore and Tananis, 2009), maintain anonymity, and achieve high response rates. This design allowed us to compare before and after perceptions from individual students, while maintaining an anonymous survey. Furthermore, most incoming students did not have prior laboratory experience outside a classroom setting. This lack of prior experience could have produced response-shift bias on their understanding of the process of scientific research, scientific analysis skills, comprehension of scientific literature, and ability to design experiments. In regard to educational goals, we discovered that the students who reported a change in their degree preference were not all interested in pursuing a more prestigious degree as would be expected to justify effort. Furthermore, the changes in degree preference were not correlated with the years the students participated in the program (Table S3).

Data collected from the 2007-2013 participants were confounded by lower 2007-2011 survey response rates, larger applicant pools for the 2012-2013 classes, and the time difference between program completion and survey submission among the 2007-2011 and 2012-2013 cohorts. Independent of these differences, the data in Figure 2 support the generality of our conclusion that extracurricular activities ignite initial interest in STEM among students who have demonstrated a strong interest and talent in STEM.

It is important to reiterate that the 2007-2013 ASSIP study population was composed of students who expressed a strong interest in STEM and acted on this interest by volunteering to perform scientific research during the summer. Our study is not a comparison of students who go into science and those who do not. Instead, the objective was to evaluate what motivates these highly successful students to pursue STEM in the first place.

Does the evidence in our study have implications beyond students who have a strong talent and interest in STEM? The findings depicted in Figures 2 and 4 underscore the important role of extracurricular experiences to ignite initial interest in STEM among students who have demonstrated a strong talent and interest in STEM. These data justify expanding this study to assess the entire diversity of students. To answer this question, we propose in a future study to assess 1) students who have participated in programs that aim to attract students into STEM, 2) recent STEM college graduates, and 3) a study population outside the northern Virginia/Washington, DC, metropolitan area.

\section{CONCLUSIONS}

The major conclusion of this study is that students who demonstrate a strong talent and interest in STEM are most influenced to become interested in STEM through extracurricular experiences. The population of students in this study reported that childhood experiences with nature, astrono$\mathrm{my}$, and so on, and relatives or friends were the strongest factors that ignited their initial interest in STEM. Hands-on 
laboratory experiences in the ASSIP correlated with a perceived sustained interest in pursuing STEM-related academic degrees and eventual employment in STEM. Our ASSIP participants perceived that they were better able to "understand material learned in the classroom and/or read in scientific literature, identify research questions and design experiments, creatively solve problems, and think critically and perform scientific analysis" after gaining hands-on research experience. These data provide insights that can influence policies and initiatives for STEM education. Because extracurricular and family experiences are highly influential as the initial attractors for students with a potential talent in STEM, community-based programs that create awareness and provide opportunities for those "magical" encounters with STEM for children and their family members should be strongly encouraged.

\section{ACKNOWLEDGMENTS}

The authors thank the mentors who provided the high school and undergraduate ASSIP participants with hands-on research experiences and the volunteers who gave career-day presentations and led workshops. They also thank the many companies and individuals who made financial contributions to the community-sponsored program. Financial support for ASSIP was provided in part by Fisher Scientific, 4-VA Life Technologies, Micron Foundation, Corning Life Sciences, the Prince William County Department of Economic Development, $\mathrm{C}^{2}$ Technologies, Lockheed Martin, Aerojet Rocketdyne, Dako, Eppendorf, Aushon Biosciences, Thermo Fisher Scientific, SySTEMic Solutions, and George Mason University.

\section{REFERENCES}

Barlow AEL, Villarejo MR (2004). Making a difference for minorities: evaluation of an educational enrichment program. J Res Sci Teach 41, 861-881.

Hall C, Dickerson J, Batts D, Kauffmann P, Bosse M (2011). Are we missing opportunities to encourage interest in STEM fields? J Technol Educ 23, 32-46.

Henderson C, Beach A, Finkelstein N (2011). Facilitating change in undergraduate STEM instructional practices: an analytic review of the literature. J Res Sci Teach 48, 952-984.

Hill LG, Betz DL (2005). Revisiting the retrospective pretest. Am J Eval 26, 501-517.

Hossain M, Robinson MG (2012). How to motivate US students to pursue STEM (science, technology, engineering and mathematics) careers. US-China Educ Rev A 4, 442-451.

Howard GS (1980). Response-shift bias a problem in evaluating interventions with pre/post self-reports. Eval Rev 4, 93-106.
Junge B, Quiñones C, Kakietek J, Teodorescu D, Marsteller P (2010). Promoting undergraduate interest, preparedness, and professional pursuit in the sciences: an outcomes evaluation of the SURE program at Emory University. CBE Life Sci Educ 9, 119-132.

Kabacoff C, Srivastava V, Robinson DN (2013). A summer academic research experience for disadvantaged youth. CBE Life Sci Educ 12, 410-418.

Kardash CM (2000). Evaluation of undergraduate research experience: perceptions of undergraduate interns and their faculty mentors. J Educ Psychol 92, 191-201.

Knox KL, Moynihan JA, Markowitz DG (2003). Evaluation of shortterm impact of a high school summer science program on students' perceived knowledge and skills. J Sci Educ Technol 12, 471-478.

Lopatto D (2004). Survey of Undergraduate Research Experiences (SURE): first findings. Cell Biol Educ 3, 270-277.

Lopatto D (2007). Undergraduate research experiences support science career decisions and active learning. CBE Life Sci Educ 6, 297-306.

Markowitz DG (2004). Evaluation of the long-term impact of a university high school summer science program on students' interest and perceived abilities in science. J Sci Educ Technol 13, 395-407.

Matyas ML, Dix LS (1992). Science and Engineering Programs: On Target for Women?, Washington, DC: National Academies Press.

Moore D, Tananis CA (2009). Measuring change in a short-term educational program using a retrospective pretest design. Am J Eval 30, 189-202.

National Science and Technology Council (2011). The Federal Science, Technology, Engineering, and Mathematics (STEM) Education Portfolio. Washington, DC: Executive Office of the President. www .whitehouse.gov/sites/default/files/microsites/ostp/costem federal_stem_education_portfolio_report.pdf (accessed 7 October 2013).

Pender M, Marcotte DE, Domingo MRS, Maton KI (2010). The STEM pipeline: the role of summer research experience in minority students' graduate aspirations. Educ Policy Anal Arch 18, 1-36.

Robinson M, Ochs GT (2008). Determining why students take more science than required in high school. Bull Sci Technol Soc 28, 338348.

Seymour E, Hunter A-B, Laursen SL, DeAntoni T (2004). Establishing the benefits of research experiences for undergraduates in the sciences: first findings from a three-year study. Sci Educ 88, 493-534.

Thiry H, Laursen SL, Hunter A-B (2011). What experiences help students become scientists? A comparative study of research and other sources of personal and professional gains for STEM undergraduates. J High Ed 82, 357-388.

Wang X (2013). Why students choose STEM majors: motivation, high school learning, and postsecondary context of support. Am Educ Res J 50, 1081-1121. 